\title{
"Chômage" dos intelectuais (*)
}

\author{
J. M. de Azevedo Marques
}

Consagrando especial atenção ás proposições da Comissão de co-operação internacional sobre o problema do "chômage" dos intelectuais, o Conselho da Ordem dos Advogados do Estado de São Paulo (Brasil) emite parecer, acudindo á solicitação da Liga das Nações e do Govêrno do Estado, para, antes de tudo, congratular-se com a nobre Associação Internacional pelo interesse que revela em tão delicado assunto, fazendo votos pelo êxito que puder conseguir para melhorar a situação atual dos intelectuais (que sofrerem do "chômage".

Nâo se furtará a repetir a impressão geral das grandes dificuldades que atormentam os bons espíritos quando, nesse particular, procuram soluções práticas.

Isso porque o "chômage" é ef eito de causas que muito dificilmente, muito demoradamente, muito parcialmente, serâo removidas, sendo algumas insoluveis e outras inccmpreensiveis.

A primeira dificuldade começa na definição exata do que seja "chômage" intelectual e a respectiva estensão.

O "chômage" não é a cessação completa e definitiva do trabalho profissional, este, como elemento indispensavel á subsistência material dos homens intelectuais.

(*) PARECER do Presidente da Ordem dos Advogados em São Paulo, por solicitação do Govêrno do Estado, para satisfazer a da Liga das Nações, aprovado pelo Conselho, unanimemente. 
Não póde ser a simples e inevitavel diminuição periódica da atividade intelectual, que se resolve pelas restrições e parcimônias no modo e no confôrto da vida; essa oscilação financeira e econômica é um fenômeno da. Natureza, inevitavel, irremediavel, previsivel, ás vezes salutar.

Queremos dizer que o "chômage" não é diminuição, é cessação temporária. Em sua origem remota, o "chômage" era aplicado tão só ás classes dirigidas, e significava "une periode de inactivité pour un établissement ou une industrie"; significava, emfim, "ne pas travailler faute d'emploi, faute d'ouvrage" Por isso H. TAINE escrevia: "Sous la riguer du climat et de la concurrence, parmi les chômages de l'industrie les faibles, les imprevoyants périssent ou s'avilissent"

Até o clima, portanto, é factor do "chômage" transitório, inevitavel, principalmente para os imprevidentes e os fracos; porque os fortes e previdentes, em regra, resistem e vencem.

Fenômenos da própria natureza, justificando o sonho histórico de José, patriarca hebreu, vendo sete vacas magras devorar sete vacas gordas e interpretando, perante Pharaó, como sete anos de fertilidade e outros tantos de penúria o que inspirou Pharaó a nomeá-lo seu primeiro ministro, o qual tomando sábias medidas preventivas e enchendo paióis, durante os anos de fartura, evitou a miséria nos anos de fome. Havia bons primeiros ministros naquela remota éra!.

E' a previdência indispensavel á vida humana, para o seu perfeito equilibrio.

A noção fundamental do "chômage", a nosso vêr, não se modificou; pretende-se, entretanto, afeiçoá-la agora aos intelectuais.

Surge, então, a segunda dificuldade:

Que é intelectual para esse efeito?

Póde-se definir como sendo a criatura humana que se caracteriza pelos dotes da inteligência, do entendimento, do 
intelecto, em oposição á que só dispõe dos dotes manuais da fôrça, ou da perícia, ou do esfôrço físico.

Mais restritamente e mais adequado ao nosso ponto de vista, chamar-se-á intelectual o ente humano que vive sómente dos seus trabalhos da inteligência. Exemplos são numerosos: o professor, o sábio, o publicista, o advogado, o médico, o cirurgião, o engenheiro, o jornalista, o poeta, o artista, o filósofo, o sacerdote, os chefes de exércitos, os chefes de Estado, os funcionários públicos dirigentes, etc., etc., enfim todos os que, analogamente, usam, indispensavelmente, da inteligência e dos conhecimentos espirituais auridos nas ciências, na história, na literatura, na sociologia, na religião, nos livros e nas letras em geral.

Ficam, pois, excluidos do grupo os que, em geral, não vivem do intelecto, mas sim dos seus outros atributos, agindo subsidiariamente, ou subservientemente, com dose imponderavel de entendimento.

Ora, se não estamos em erro, conclue-se que a classe dos intelectuais, é extremamente numerosa, mais exigente mais necessitada de meios financeiros, mais cara, porque, justamente, despende mais, produz maiores benefícios á humanidade; sustenta enfim o outro grupo, embora não o possa dispensar. Alma num corpo.

Como exemplo irresistivel, lembraremos um só nome: PASTEUR, o imortal, que operou e operará eternamente, diariamente, a sálvação de incontavel número de vidas racionais e irracionais!. Diante desse intelectual a Humanidade se ajoelha!.

Em suma: os intelectuais geram, criam, o que ha de mais sublime, de mais vital, independentemente do subsídio posterior, embora indispensavel, do outro grupo social, o qual, dirigido, dá corpo e consistência a um grande número de produtos da inteligência. Assim, não se dirá que o fabricante de papel, ou o tipógrafo impressor, ou o serralheiro, ou o carpinteiro, que fazem a impressão e divulgação das obras primas de Beethoven, Mozart, Dante e mil outros gênios, ou os que fabricaram os aviões de SANTos Dumont 
para descobrir a navegação aérea, sejam iguais ou siquer aproximados dos criadores.

Por isso, nã்o pareca paradoxo afirmar-se que a assistência social, no caso de "chômage", do segundo grupo é mais necessária, é mais facil, menos onerosa, mais possivel. 0 grupo intelectual engendra a própria defesa: a previdência, a economia, a prudência, a vontade de amealhar, a visão das vacas magras, que esse grupo, mais ilustre, sente melhor do que o sente o segundo.

Ora, a assistência eficaz e completa aos "chômeurs" intelectuais teria de pesar sobre o outro grupo mais fraco, o dos não intelectuais, que forma o restante da colectividade!.

Como? Por que? Desde que a colectividade se biparte em dois grupos, ou em dois valores sociais: - o manual e o intelectual -, só aquele terá de socorrer a este quando estiver em "chômage" Não vemos outra fonte, porque os cofres do Estado só dispõem dos tributos que lhe fornece a atividade produtiva. O Estado é simples depositário: só para o que recebe. Se, pois, um dos grupos nada produz, nem siquer para se manter e cái em "chômage", nada poderá fornecer ao Estado. Êste terá que pedir ao grupo restante, embora de modo indireto. E então surge o aumento geral do custo da vida como consequência irremovivel e absurda. E' o círculo vicioso.

Todos os regimens novos de assistência após a grande guerra de 1914-1918 têm sido contraproducentes, causando agravação da vida: aumento do preço da alimentação, do vestuário, do transporte, de tudo que é indispensavel á subsistência, e, portanto, o mal-estar, o empobrecimento geral, inclusivamente a desvalorização do agente aquisitivo que é a moeda.

Antes da guerra as relações entre a economia e o Estado tinham importância secundária. A economia permanecia reservada á iniciativa individual; a atividade econômica era sempre de interêsse privado sem embargo de certas modalidades de intervenção protetora do Estado para 
maior eficiência dos direitos das classes dirigidas. A guerra, porém, fez piorar tudo pela natural razão de que foi ela mesma quem arruinou, e destruiu. A famosa "economia dirigida" fracassou desde que não trouxe tranquilidade, barateamento, confiança, estabilidade e paz, nem ao Estado nem ao individuo; tanto assim que, decorridos vinte anos, ainda nada se conseguiu de definitivo e de calmante; as reclamações, descontentamentos, sofrimentos e projetos, continuam insoluveis, tormentosos, múltiplos, entre os quais aparece agora surpreendente o "chômage" até dos "intelectuais"!. E' a "moda" E' mais do que intranquilidade; é sim, ansiedade, dor, asfixía.

Parece um desvio de lógica e de observação supôr que haja uma fórmula específica e milagrosa de assistência entre o Estado e todos os indivíduos, além das fórmulas restritas a casos particulares, isto é, a assistência devida pela sociedade política aos seus membros incapazes de provêr á própria existência pelo seu trabalho ou pelos seus capitais, por exemplo: os menores abandonados, os mutilados, os enfermos pobres, os inválidos, os velhos, as mulheres durante a gestação, etc. etc. E' a lei moral - caritas generis humanum - que o Estado executa em nome e com us recursos de todos os seus membros, concretizados nos impostos e tributos fiscais diretos e indiretos. Sempre existiu no proprio Direito privado, por exemplo, a assistência entre parentes, e o consagra, como os outros, o nosso Código Civil nos artigos 396-405.

Recentemente, ampliações têm sido introduzidas, algumas sensatas, nas chamadas leis do trabalho, as caixas de socorros, de assistência, etc. etc., públicas e particulares.

Mas, quando se pensa no imenso grupo dos intelectuais a dificuldade atemoriza.

Nos paizes em que a falta de trabalhos intelectuais retribuidos for geral e intensa, quais seriam os melhores meios legais e compulsórios para aumentar a atividade dos intelectuais e, portanto, os seus proventos pecuniários? 
Como aumentar, por exemplo, o movimento forense para aumentar os clientes dos advogados? Como aumentar os doentes abastados para os médicos? Como aumentar obras e empreendimentos para os arquitetos e engenheiros? Como obrigar os intelectuais superabundantes a mudar de profissão preferindo até a de campezino? Ou a causa será não a falta de trabalho, mas superprodução de trabalhadores intelectuais? Como diminuir essa superprodução do intelecto? Fechando durante certo tempo as Academias que diplomam profissionais? Tornando gratúita a Justiça, e, portanto, suprimindo rendas dos Estados, os quais, em geral e a seu turno, já estão em situação de "chômage", e mal dispõem de dinheiro para aumentar armamentos de morte e destruição e de defesa?!.

0 "chômage" dos intelectuais é parcial, relativo, variavel de país a país.

Ainda ha, com certeza no Brasil, e haverá noutras nações, um grande número de intelectuais bem conhecidos que prosperam na profissão; e sem sair do pequeno âmbito da nossa província e sem sair do dia de hoje, existem intelectuais distintos pela inteligência, pela fama, pela argúcia, pelo saber, que espontânea e livremente acabam de trocar cargos vitalícios, da magistratura, bem remunerados, pela cátedra da advocacia e do professorado. Onde, em que país, em que classe de homens, em quais profissões não ha hoje o "chômage"? E' uma epidemia.

A causa verdadeira, dizem-no pensadores e escritor's, é a consequência natural da grande guerra terminada nominalmente em 1918, e, mais atual, a situação de lutas armadas deste momento, com ameaças e perturbações visíveis e profundas na vida humana. Numa palavra: é a ausência da paz. Sem paz é impossivel o trabalho eficaz, acumulador de riquezas, creador de movimento, de intercâmbio, de felicidade.

Axioma este banal. A paz fecundante não deve limitar-se a uma bela mística, ou uma paz de cinema. Dispensamo-nos de repetir á ilustre Assembléia das Nações, cuja 
principal finalidade é a de impôr a paz, o que ela está farta de conhecer, isto é, o problema de causalidade. Cessem as causas, que são artificiais e cessarão os efeitos. A crise é generalizada, insensivel ás medicações locais; é mental.

Para terminar informraremos que, em relação á profissão intelectual da advocacia, o Estado de São Paulo já fez, por iniciativa do Conselho da Ordem, alguma coisa: criou uma Caixa de Auxílio pecuniário aos advogados necessitados por invalidez, enfermidade ou penúria.

O seu patrimônio é formado pelos proventos regimentais que cabem aos advogados em todos os processos judiciais; e já tem auxiliado não poucos. Praza aos Céus que o tempo permita melhorar a instituição, mas sem onerar o povo, sem agravar as suas contribuições compulsórias, sem novos impostos, cujo aumento, crescente e instavel, de ano a ano, vai de mais a mais dificultando a vida, tornando temeroso o problema da tranquilidade, da estabilidade, e, em suma, da paz de espírito, sem a qual não ha paz politica.

Falando á douta Sociedade das Nações não precisavamos siquer estas ligeiras linhas para fazer votos pelo bom sucesso, prático, justo e inócuo, relativamente ao delicado problema, por mais insoluvel que seja, ou pareça ser, até que no Mundo se restabeleça a Paz. 